\title{
Groundwater Exploitation Zoning Aiming at Management of Sustainable Groundwater Exploitation and Use in Ca Mau Peninsula, Vietnam
}

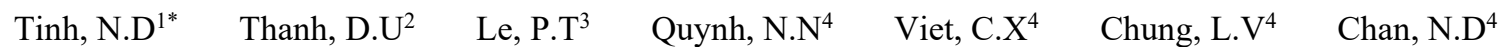 \\ 1.Thuyloi University, 02 Truong Sa Street, HoChiMinh City, Vietnam \\ 2.Faculty of Geology and Petroleum Engineering, Hochiminh City University of , 268 Ly Thuong Kiet street, \\ HoChiMinh city, Vietnam \\ 3.Danang Water Supply Joint Stock Company, Danang, Vietnam \\ 4.Division for Water Resources Planning and Investigation for the South of Vietnam, HoChiMinh city, Vietnam
}

The research is financed by KC08.08/16-20: Study of measures for mitigating and adapting to drought and salinity intrusion as natural hazards in Camau peninsula, Ministry of Science and Technology, Vietnam

\section{Abstract}

Groundwater system in Camau Peninsula has 6 main aquifers (not including very poorly productive qh aquifer), of which 4 aquifers are predominantly exploited, namely $\mathrm{qp}_{2-3}, \mathrm{qp}_{1}, \mathrm{n}_{2}^{2}$ and $\mathrm{n}_{2}{ }^{1} ; 2$ minor aquifers are $\mathrm{qp}_{3}$ and $\mathrm{n}_{1}{ }^{3}$. Although the aquifers are located over the area, due to complicated fresh/saline interfaces in sections, exploitation and protection of groundwater sources is dealing with many problems. In the paper, information of aquifers is systematized into a map of groundwater exploitation zoning on scale 1:200,000 for the purpose of supplying essential information of water sources management in each socio-economical zone.

Keywords: Camau peninsula, potential exploitable groundwater reserve.

DOI: $10.7176 / \mathrm{JEES} / 10-4-04$

Publication date: April $30^{\text {th }} 2020$

\section{Introduction}

In traditional hydrogeological study, special information is synthesized and displayed with hydrogeological maps. Hydrogeological maps are composed in accordance with Vietnam technical regulations, so they are sophisticatedly and exploitation of information from them (reading and understanding) faces certain difficulties. Actually, managers and people with no sound special background have troubles in adequate perceiving of information displayed on hydrogeological maps. In previous projects of Department of Geology and Minerals of Vietnam, people have tried to simplify presentation of special information with maps of potential groundwater exploitation (Chan, 2010; Linh, 1992; Tuan \&Chan, 1992). In these maps, contents of information have been simplified, but some other contents of sophisticated specialty were added. Therefore, their popularity is not so high.

In studying distribution of groundwater reserve of an area, people rely on maps that contain synthesized information of reserve. This paper assesses potential of groundwater use based on map of groundwater exploitation zoning. On this map, the area in question will be divided into regions having similarity of distribution laws of aquifers and its exploitation potential. Besides, for the purpose of management and reasonable use of water sources, ecological regions will be attached, aiming at supplying information for development planning of fields which have water demand.

Studies in this paper inherit ideas of map of groundwater exploitation potential and study of criteria of exploitation zoning in Hien (2009). Intermediate processing will be combined for presenting necessary information in simple way so people can approach easily.

\section{Overall of groundwater system of camau peninsula}

Results of the scientific research of state level KC08.08/16-20 (Study of measures for mitigating and adapting to drought and salinity intrusion as natural hazards in Camau peninsula) show that in Camau peninsula exist 7 granular aquifers, being: Holocene ( $q$ h), Upper Pleistocene ( $\left.\mathrm{qp}_{3}\right)$, Middle-Upper Pleistocene ( $\mathrm{qp}_{2-3}$ ), Lower Pleistocene $\left(\mathrm{qp}_{1}\right)$, Middle Pliocene $\left(\mathrm{n}_{2}^{2}\right)$, Lower Pliocene $\left(\mathrm{n}_{2}{ }^{1}\right)$ and Upper Miocene $\left(\mathrm{n}_{1}^{3}\right)$. Distribution features of aquifers are presented in Tables 1 and 2. 
Table 1. Areal distribution features of aquifers

\begin{tabular}{|c|c|r|r|r|r|r|r|r|r|r|}
\hline \multirow{2}{*}{$\#$} & \multirow{2}{*}{ Aquifers } & \multirow{2}{*}{$\begin{array}{c}\text { Distribution } \\
\text { area }\left(\mathrm{km}^{2}\right)\end{array}$} & \multicolumn{9}{|c|}{ Distribution area of regions $\left(\mathrm{km}^{2}\right)$} \\
\cline { 7 - 12 } & & 8,052 & 3,826 & 1,482 & 1,558 & 181 & 183 & 18 & 602 & 201 \\
\hline 1 & $\mathrm{qh}$ & 14,545 & 4,332 & 1,482 & 1,923 & 968 & 2,177 & 1,025 & 1,086 & 1,553 \\
\hline 2 & $\mathrm{qp}_{3}$ & 16,564 & 4,332 & 1,482 & 2,083 & 1,132 & 2,177 & 1,053 & 1,254 & 3,051 \\
\hline 3 & $\mathrm{qp}_{2-3}$ & 16,600 & 4,332 & 1,482 & 2,082 & 1,132 & 2,177 & 1,052 & 1,359 & 3,052 \\
\hline 4 & $\mathrm{qp}_{1}$ & 16,092 & 4,332 & 1,482 & 2,082 & 1,132 & 1,639 & 1,015 & 1,358 & 3,051 \\
\hline 5 & $\mathrm{n}_{2}{ }^{2}$ & 15,580 & 4,332 & 1,482 & 2,082 & 1,132 & 1,448 & 688 & 1,365 & 3,051 \\
\hline 6 & $\mathrm{n}_{2}{ }^{1}$ & 14,111 & 4,149 & 1,482 & 2,082 & 1,132 & 572 & 286 & 1,357 & 3,051 \\
\hline 7 & $\mathrm{n}_{1}{ }^{3}$ & &
\end{tabular}

Table 2. Depth distribution features of aquifers

\begin{tabular}{|r|c|r|r|r|r|r|r|r|r|r|}
\hline \multirow{2}{*}{$\#$} & \multirow{2}{*}{ Aquifers } & \multicolumn{3}{|c|}{ Top depth $(\mathrm{m})$} & \multicolumn{3}{c|}{ Bottom depth $(\mathrm{m})$} & \multicolumn{3}{c|}{ Thickness $(\mathrm{m})$} \\
\cline { 3 - 12 } & & \multicolumn{1}{|c|}{ From } & \multicolumn{1}{|c|}{ To } & \multicolumn{1}{|c|}{ Avg. } & \multicolumn{1}{c|}{ From } & \multicolumn{1}{c|}{ To } & \multicolumn{1}{c|}{ Avg. } & \multicolumn{1}{c|}{ From } & \multicolumn{1}{c|}{ To } & \multicolumn{1}{c|}{ Avg. } \\
\hline 1 & $\mathrm{qh}$ & 0.0 & 61.0 & 19.6 & 8.0 & 75.0 & 30.8 & 0.6 & 65.0 & 11.3 \\
\hline 2 & $\mathrm{qp}_{3}$ & 20.0 & 94.5 & 46.3 & 29.0 & 162.0 & 71.7 & 1.9 & 122.4 & 25.6 \\
\hline 3 & $\mathrm{qp}_{2-3}$ & 44.0 & 162.0 & 85.1 & 62.2 & 207.0 & 127.2 & 2.0 & 109.5 & 42.1 \\
\hline 4 & $\mathrm{qp}_{1}$ & 85.5 & 226.0 & 147.0 & 108.0 & 287.2 & 186.9 & 3.0 & 110.2 & 39.9 \\
\hline 5 & $\mathrm{n}_{2}{ }^{2}$ & 130.0 & 310.6 & 210.6 & 144.0 & 334.0 & 256.9 & 3.0 & 133.0 & 46.3 \\
\hline 6 & $\mathrm{n}_{2}{ }^{1}$ & 149.0 & 363.3 & 283.4 & 180.0 & 408.7 & 328.6 & 10.0 & 139.0 & 45.3 \\
\hline 7 & $\mathrm{n}_{1}{ }^{3}$ & 285.4 & 508.0 & 378.0 & 313.5 & 602.0 & 442.3 & 6.5 & 129.0 & 64.2 \\
\hline
\end{tabular}

Potential exploitable groundwater reserves were evaluated for 6 perspective aquifers, being: $\mathrm{qp}_{3}, \mathrm{qp}_{2-3}, \mathrm{qp}_{1}$, $\mathrm{n}_{2}{ }^{2}, \mathrm{n}_{2}{ }^{1}$ and $\mathrm{n}_{1}{ }^{3}$. Aquifer qh has narrow distribution area, small thickness and poor productivity, so it was neglected. Potential exploitable fresh groundwater reserve for entire Camau peninsula was calculated after balance method as $11,340,102 \mathrm{~m}^{3} / \mathrm{day}$, rounded as: $11,340,100 \mathrm{~m}^{3} /$ day. In details: Static gravitational reserve: $8,972,925 \mathrm{~m}^{3} / \mathrm{day}$, rounded as $8,972,900 \mathrm{~m}^{3} /$ day; static elastic reserve: $870,231 \mathrm{~m}^{3} /$ day, rounded as: $870,200 \mathrm{~m}^{3} /$ day and dynamic reserve: $1,496,947 \mathrm{~m}^{3} /$ day, rounded as $1,497,900 \mathrm{~m}^{3} /$ day. Potential exploitable groundwater reserves of each ecological region are presented in Table 3. Dynamic reserves are presented in Table 4.

Table 3. Potential fresh groundwater exploitable reserve

\begin{tabular}{|c|c|c|c|c|c|c|c|c|c|}
\hline \multirow{2}{*}{ Aquifers } & \multicolumn{8}{|c|}{ Potential fresh groundwater exploitable reserve $\left(\mathrm{m}^{3} / \mathrm{day}\right)$} & \multirow{2}{*}{ Total ( $\mathrm{m}^{3} /$ day $)$} \\
\hline & $\mathbf{A}$ & B1 & B2 & B3 & C1 & $\mathrm{C2}$ & D & $\mathbf{E}$ & \\
\hline $\mathrm{qp}_{3}$ & 433,679 & 170,785 & 36,575 & 0 & 0 & 0 & 14,571 & 0 & 655,611 \\
\hline $\mathrm{qp}_{2-3}$ & 887,558 & 387,348 & 532,591 & 322,987 & 544,772 & 242,478 & 329,285 & 529,664 & $3,776,684$ \\
\hline $\mathrm{qp}_{1}$ & 439,591 & 279,629 & 394,524 & 313,125 & 311,600 & 248,521 & 403,621 & 627,469 & $3,018,079$ \\
\hline $\mathrm{n}_{2}{ }^{2}$ & 198,225 & 115,277 & 202,120 & 321,117 & 237,426 & 154,507 & 209,349 & 394,273 & $1,832,295$ \\
\hline $\mathrm{n}_{2}{ }^{1}$ & 568,309 & 703 & 155,106 & 201,224 & 124,264 & 0 & 150,957 & 143,250 & $1,343,814$ \\
\hline $\mathrm{n}_{1}{ }^{3}$ & 146,056 & 127,137 & 334,778 & 93,914 & 702 & 0 & 11,033 & 0 & 713,620 \\
\hline Total & $2,673,420$ & $1,080,879$ & $1,655,694$ & $1,252,367$ & $1,218,764$ & 645,506 & $1,118,816$ & $1,694,656$ & $11,340,102$ \\
\hline
\end{tabular}

Table 4. Dynamic reserves in ecological regions

\begin{tabular}{|c|c|c|c|c|c|c|c|c|c|}
\hline \multirow[b]{2}{*}{ Aquifers } & \multicolumn{8}{|c|}{ Dynamic reserves in ecological regions ( $\mathrm{m}^{3} /$ day) } & \multirow{2}{*}{$\begin{array}{c}\text { Total } \\
\left(\mathrm{m}^{3} / \text { day }\right)\end{array}$} \\
\hline & A & B1 & $\mathrm{B} 2$ & B3 & $\mathrm{C} 1$ & $\mathrm{C} 2$ & $\mathrm{D}$ & E & \\
\hline $\mathrm{qp}_{3}$ & 97,711 & 67,940 & 8,273 & 0 & 0 & 0 & 2,588 & 0 & 176,512 \\
\hline $\mathrm{qp}_{2-3}$ & 146,178 & 84,347 & 95,811 & 22,118 & 67,486 & 41,624 & 79,316 & 44,916 & 581,796 \\
\hline $\mathrm{qp}_{1}$ & 19,834 & 25,243 & 36,245 & 20,715 & 17,899 & 26,553 & 78,148 & 106,712 & 331,350 \\
\hline $\mathrm{n}_{2}^{2}$ & 11,715 & 8,239 & 19,966 & 38,022 & 15,100 & 19,825 & 31,293 & 96,062 & 240,221 \\
\hline $\mathrm{n}_{2}{ }^{1}$ & 30,433 & 0 & 17,706 & 16,602 & 8,084 & 0 & 29,266 & 22,263 & 124,355 \\
\hline $\mathrm{n}_{1}^{3}$ & 14,393 & 14,374 & 8,528 & 2,116 & 702 & 0 & 2,600 & 0 & 42,713 \\
\hline Total & 320,265 & 200,142 & 186,529 & 99,573 & 109,270 & 88,002 & 223,212 & 269,952 & $1,496,947$ \\
\hline
\end{tabular}

Remark: Ecological regions A, B1, B2, B3, C1, C2, D and E were taken, referred to documents of Southern Institute of Water Resources Planning (2007) as displayed in Figure 1a.

\section{Method of groundwater exploitation zoning in camau peninsula}

\subsection{Method of zoning}

Map of groundwater exploitation zoning was composed in accordance with the principle: water demand for development and perspective of groundwater exploitation. After this principle, the study area is divided based on the following criteria:

- Water demand for development (demand of water use in ecological regions). 
- Perspective of fresh groundwater exploitation (is there perspective of good quality groundwater exploitation?).

- Satisfaction level of water demand for domestic and production purposes (potential of groundwater source and satisfaction level).

\section{2- Basis of groundwater exploitation zoning mapping}

a- Topographical base map: Topographical base map used for mapping is topographical map of system VN-2000 on scale 1:200,000. Information shown are: Locations and names of cities, provinces, districts, communes, hamlets, rivers, coordinate grid, provincial boundaries, elevation marks, transportation system (ground, asphalt routes), water network, lakes, ponds....

b- Hydrogeological base map: Hydrogeological base map of the same scale 1:200,000. Boundaries and special information were extracted from this base map.

\section{Contents and presentation method}

\subsection{Contents}

In the study area there are combinations of one or multiple aquifers that have potential to meet water demand for domestic and production purposes. May be a case that in this locality a definite aquifer plays utmost important role, but in other locality it has a minor role or does not exist. In the entire area there are 6 aquifers (aquifer qh is neglected), of which potential of fresh groundwater exploitation is focused on 4 main aquifers, being: $\mathrm{qp}_{2-3}, \mathrm{qp}_{1}$, $\mathrm{n}_{2}{ }^{2}$ and $\mathrm{n}_{2}{ }^{1}$. Aquifers $\mathrm{qp}_{3}$ and $\mathrm{n}_{1}{ }^{3}$, although can be exploited for fresh water of good quality, but considered as minor due to:

- Aquifer $\mathrm{qp}_{3}$ : small thickness, can be exploited on household scale.

- Aquifer $\mathrm{n}_{1}^{3}$ : Large thickness and productive, but because of deep distribution and large exploitation investment, they are considered as minor.

Based on this principle the Camau peninsula is divided into 3 main units downwards as follows:

Exploitation region: is divided usually after criterion of purpose of exploitation of water sources for social economical development. In 2007, Southern Institute of Water Resources Planning divided Camau peninsula into 8 ecological regions based on water resources and production pattern (symbolized as: A, B1, B2, B3, C1, C2, D and E), and this paper inherits this result (Figure 1a).

Exploitation area: is divided after perspective of fresh groundwater exploitation (fresh groundwater can be exploited or fresh groundwater is not available), see details in Figure $1 \mathrm{~b}$.

- Area of perspective fresh groundwater exploitation (at least 1 fresh aquifer), refered to as (I), symbol: I.

- Area of no perspective for fresh groundwater exploitation (all aquifers are saline), refered to as (II), symbol: II. Exploitation plot: is divided after level of satisfaction for water demand for domestic and production purposes. Criteria are number of main aquifers and potential groundwater exploitable reserve.

- Plot I-1 - Scarce: one fresh aquifer ( $\left.\mathrm{qp}_{2-3}\right)$.

- Plot I-2 - medium: two fresh aquifers $\left(\mathrm{qp}_{2-3}\right.$ and $\left.\mathrm{qp}_{1}\right)$.

- Plot I-3 - Rich: three fresh aquifers $\left(\mathrm{qp}_{2-3}, \mathrm{qp}_{1}\right.$ and $\left.\mathrm{n}_{2}^{2}\right)$.

- Plot I-4 - abundant: four fresh aquifers $\left(\mathrm{qp}_{2-3}, \mathrm{qp}_{1}, \mathrm{n}_{2}{ }^{2}\right.$ and $\left.\mathrm{n}_{2}{ }^{1}\right)$.

Area II was not divided into plot.

4.2 Implementation method Contents

On the basis of the mentioned principle and study results of the research, we composed map of groundwater exploitation zoning after following procedure:

Step 1: Determination of groundwater exploitation regions

- Compilation of groundwater exploitation regions, determination of distribution range, boundaries, areas

- Calculation of groundwater exploitable reserve for each region (potential groundwater exploitable reserve and secure exploitable groundwater reserve).

Step 2: Determination of groundwater exploitation areas and plots

- Superimposition fresh-saline boundaries (TDS $=1 \mathrm{~g} / \mathrm{l}$ ) of 4 main aquifers $\mathrm{qp}_{2-3}, \mathrm{qp}_{1}, \mathrm{n}_{2}{ }^{2}$ and $\mathrm{n}_{2}{ }^{1}$. Determination of areas and plots: range and area, see details in Figure 2

- Calculation of groundwater reserve for each plot (potential groundwater exploitable reserve and secure exploitable groundwater reserve),

Step 3: Determination of range of possible fresh water exploitation of minor aquifers

- Determination of fresh water distribution based on fresh-saline boundaries (TDS $=1 \mathrm{~g} / \mathrm{l}$ ) of aquifers,

- In each exploitation plot, calculation of groundwater reserve for each aquifer (potential groundwater exploitable reserve and secure exploitable groundwater reserve).

Step 4: Composition of map of groundwater exploitation zoning

- Draft of map legend,

- Superimposition of maps as implemented in previous steps,

- To bring special information into the map. 
Implementation results are displayed in Figure 3.

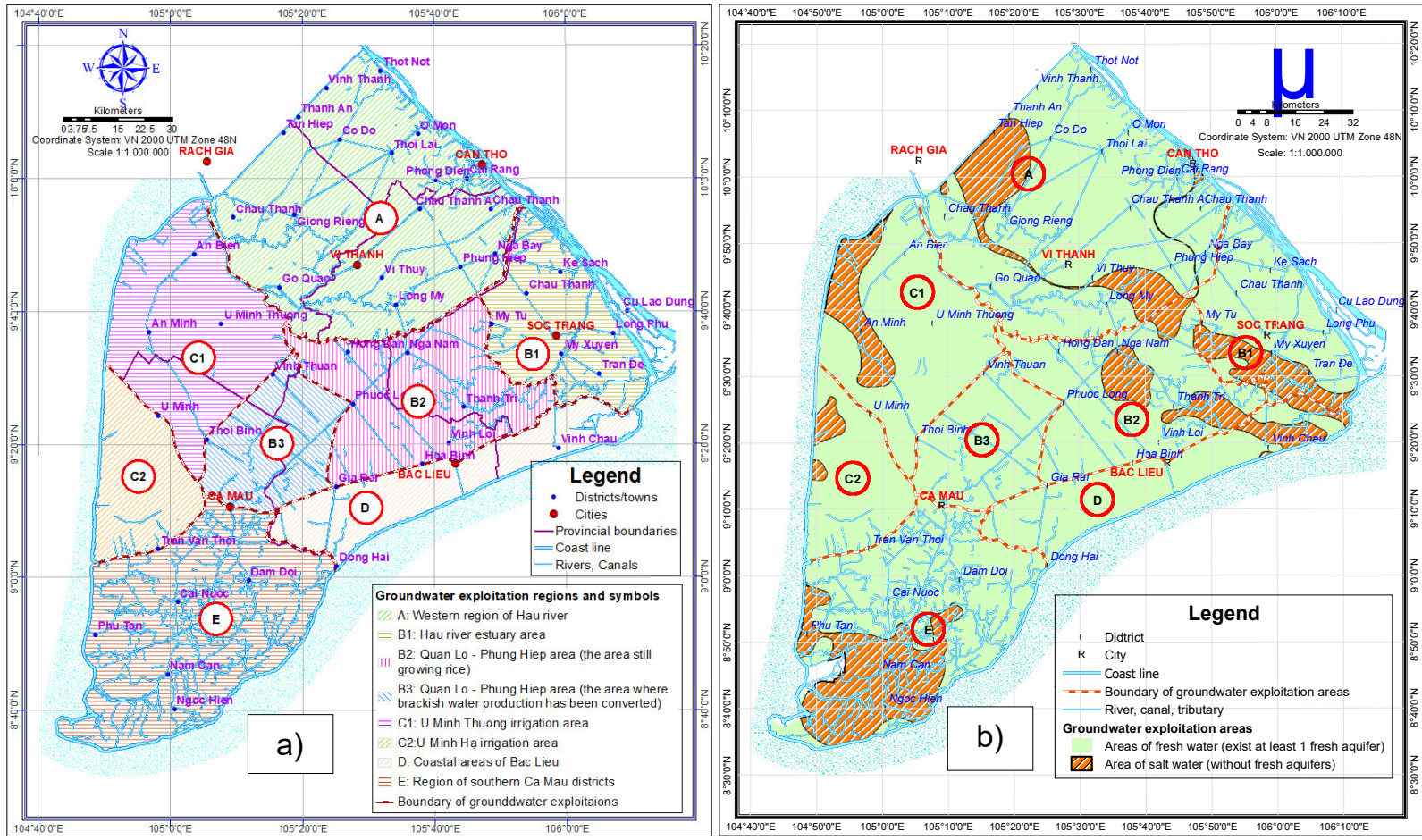

Figure 1. Map of Groundwater Exploitation Regions (a) and map of Perspective Groundwater Exploitation Areas (b)

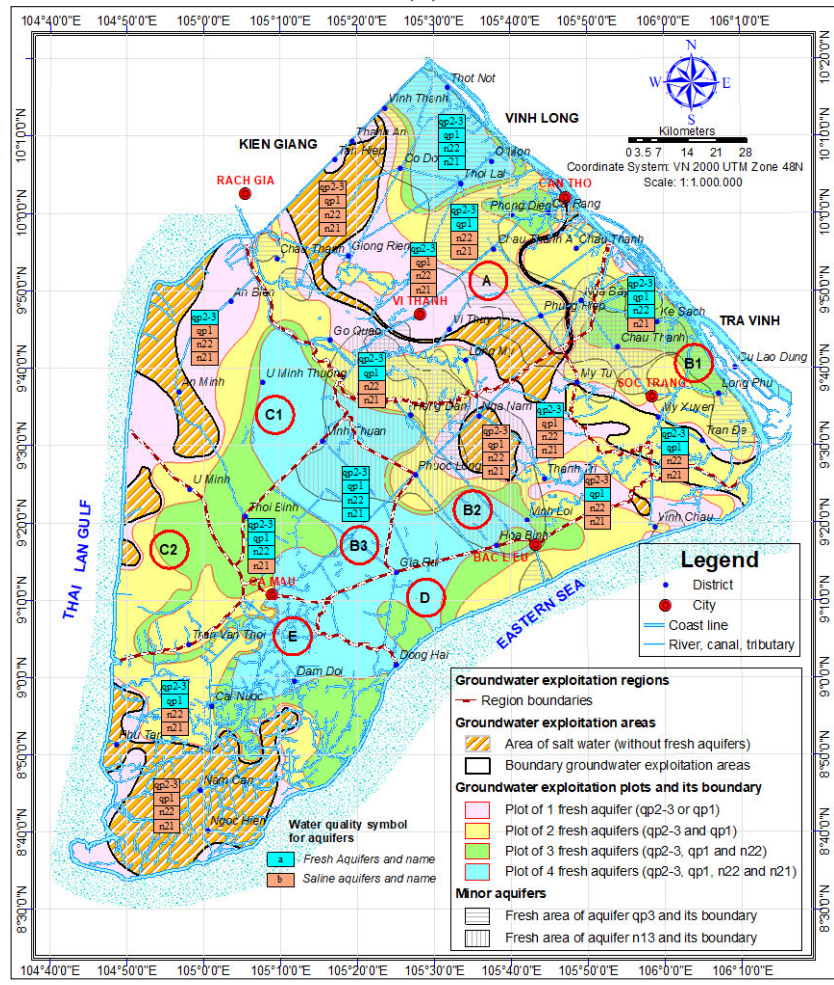

Figure 2. Map of Groundwater Exploitation Plots

\section{Results and discussion}

From the entire Camau peninsula, area from which fresh groundwater can be exploited is $13,871.9 \mathrm{~km}^{2}(83.6 \%)$. Area of saline groundwater is $2,728.1 \mathrm{~km}^{2}(16.4 \%)$. Potential fresh groundwater exploitable reserve is $11,340,102 \mathrm{~m}^{3} /$ day (of which, fresh groundwater secure exploitable reserve is $741,534 \mathrm{~m}^{3} /$ day, approximately $6.5 \%$ of potential fresh groundwater exploitable reserve). Potential saline groundwater exploitable reserve is 
$4,865,900 \mathrm{~m}^{3} /$ day. In area range of fresh water (area I), potential exploitable groundwater reserve of each plot is different:

- Scarce plot: Fresh groundwater can be exploited only from aquifer qp2-3 in total range of $2,844.8 \mathrm{~km}^{2}$.

- Medium plot: Fresh groundwater can be exploited from aquifers $\mathrm{qp}_{2-3}$ and $\mathrm{qp}_{1}$ in total range of $4,832.6 \mathrm{~km}^{2}$.

- Rich plot: Fresh groundwater can be exploited from aquifers $\mathrm{qp}_{2-3}, \mathrm{qp}_{1}, \mathrm{n}_{2}{ }^{2}$ and $\mathrm{n}_{2}{ }^{1}$ in total range of $2,847.1 \mathrm{~km}^{2}$.

- Abundant plot: Fresh groundwater can be exploited from aquifers $\mathrm{qp}_{2-3}, \mathrm{qp}_{1}, \mathrm{n}_{2}{ }^{2}$ and $\mathrm{n}_{2}{ }^{1}$ in total range of $3,377.5 \mathrm{~km}^{2}$.

Specifications of exploitation regions are shown in details in Table 5 and Figure 3.

Table 5. Specifications of exploitation regions

\begin{tabular}{|c|c|c|c|c|c|c|c|c|}
\hline \multicolumn{2}{|c|}{ Region } & \multicolumn{4}{|c|}{ Area } & \multicolumn{2}{|c|}{ Plot } & \multirow{3}{*}{ Perspective } \\
\hline \multirow{2}{*}{ Symbol } & \multirow{2}{*}{$\begin{array}{c}\text { Area } \\
\left(\mathrm{km}^{2}\right)\end{array}$} & \multirow{2}{*}{ Symbol } & \multirow{2}{*}{$\begin{array}{l}\text { Area } \\
\left(\mathrm{km}^{2}\right)\end{array}$} & \multicolumn{2}{|c|}{ Reserve (m³/day) } & \multirow{2}{*}{ Symbol } & \multirow{2}{*}{$\begin{array}{l}\text { Area } \\
\left(\mathrm{km}^{2}\right)\end{array}$} & \\
\hline & & & & Potential & Secure & & & \\
\hline \multirow{5}{*}{ A } & \multirow{5}{*}{$4,200.0$} & \multirow{4}{*}{ A-I } & \multirow{4}{*}{$3,697.3$} & \multirow{4}{*}{$2,673,420$} & \multirow{4}{*}{151,141} & A-I-1 & $1.192,1$ & Scarce \\
\hline & & & & & & A-I-2 & $1.701,0$ & Medium \\
\hline & & & & & & A-I-3 & 279,6 & Rich \\
\hline & & & & & & A-I-4 & 524,6 & Abundant \\
\hline & & A-II & 502.7 & $4,309,363$ & & & & No fresh GW \\
\hline \multirow{4}{*}{ B1 } & \multirow{4}{*}{$1,560.0$} & \multirow{3}{*}{ B1-I } & \multirow{3}{*}{$1,219.0$} & \multirow{3}{*}{$1,080,879$} & & B1-I-1 & 148,8 & Scarce \\
\hline & & & & & 112,263 & B1-I-2 & 612,0 & Medium \\
\hline & & & & & & B1-I-3 & 458,2 & Rich \\
\hline & & B1-II & 341.0 & $1,593,786$ & & & & No fresh GW \\
\hline & & & & & & B2-I-1 & 417,5 & Scarce \\
\hline & & & & & & B2-I-2 & 518,1 & Medium \\
\hline B2 & $1,950.0$ & B2-I & $1,646.7$ & $1,655,694$ & 115,208 & B2-I-3 & 148,8 & Rich \\
\hline & & & & & & B2-I-4 & 562,3 & Abundant \\
\hline & & B2-II & 303.3 & $1,730,405$ & & & & No fresh GW \\
\hline & & & & & & B3-I-2 & 35,6 & Medium \\
\hline & & B3-I & $1,200.0$ & $1,252,367$ & 78,518 & B3-I-3 & 337,9 & Rich \\
\hline B3 & $1,200.0$ & & & & & B3-I-4 & 826,5 & Abundant \\
\hline & & B3-II & 0.0 & 514,495 & & & & No fresh GW \\
\hline & & & & & & C1-I-1 & 661,2 & Scarce \\
\hline & & C1-I & 18150 & 1218764 & 41254 & C1-I-2 & 271,0 & Medium \\
\hline C1 & $2,200.0$ & C1-1 & $1,815.0$ & $1,218, / 64$ & 41,254 & C1-I-3 & 377,3 & Rich \\
\hline & & & & & & C1-I-4 & 505,5 & Abundant \\
\hline & & C1-II & 385.0 & $1,460,362$ & & & & No fresh GW \\
\hline & & & & & & C2-I-1 & 100,8 & Scarce \\
\hline C) & & C2-I & 1.000 .2 & 645,506 & 30,095 & C2-I-2 & 557,0 & Medium \\
\hline $\mathrm{C2}$ & $1,100.0$ & & & & & C2-I-3 & 342,4 & Rich \\
\hline & & C2-II & 99.8 & 780,035 & & & & No fresh GW \\
\hline & & & & & & D-I-1 & 35,2 & Scarce \\
\hline & & $D_{-}$ & 12805 & 1118816 & 80884 & D-I-2 & 492,7 & Medium \\
\hline D & 1.500 .0 & $D-1$ & 1,289.5 & $1,118,810$ & 80,884 & D-I-3 & 319,0 & Rich \\
\hline & & & & & & D-I-4 & 442,6 & Abundant \\
\hline & & D-II & 210.6 & $1,167,337$ & & & & No fresh GW \\
\hline & & & & & & E-I-1 & 289,2 & Scarce \\
\hline & & E-I & 20343 & 1694656 & 132172 & E-I-2 & 645,2 & Medium \\
\hline $\mathbf{E}$ & $2,950.0$ & & & $1,694,056$ & $132,1 / 2$ & E-I-3 & 583,9 & Rich \\
\hline & & & & & & E-I-4 & 516,0 & Abundant \\
\hline & & E-2 & 915.7 & $3,310,117$ & & & & No fresh GW \\
\hline & & & & & & I-1 & $2.844,8$ & Scarce \\
\hline & & $\mathbf{I}$ & 138710 & 11240102 & & I-2 & $4.832,6$ & Medium \\
\hline Overall & $16,600.0$ & 1 & $13,871.9$ & $11,340,102$ & 741,534 & I-3 & $2.847,1$ & Rich \\
\hline & & & & & & $\mathrm{I}-4$ & $3.377,5$ & Abundant \\
\hline & & II & $2,728.1$ & $14,865,900$ & & & & No fresh GW \\
\hline
\end{tabular}

Besides, in each region fresh groundwater in also can be exploited from minor aquifers as follows:

- Aquifer $\mathrm{qp}_{3}$ has fresh groundwater area $2,756.5 \mathrm{~km}^{2}$ and potential exploitable reserve $655,611 \mathrm{~m}^{3} /$ day.

- Aquifer $\mathrm{n}_{1}^{3}$ has fresh groundwater area $2,350.8 \mathrm{~km}^{2}$ and potential exploitable reserve $713,620 \mathrm{~m}^{3} / \mathrm{day}$. 
Specifications of minor aquifers in exploitation regions are listed in Table 6 and its distribution ranges are displayed in Figure 2.

Table 6. Specifications of minor aquifers in exploitation regions

\begin{tabular}{|c|c|c|c|c|c|c|}
\hline \multirow{2}{*}{$\begin{array}{l}\text { Exploitation } \\
\text { regions }\end{array}$} & \multicolumn{2}{|c|}{ Area of fresh water $\left(\mathrm{km}^{2}\right)$} & \multicolumn{2}{|c|}{$\begin{array}{l}\text { Potential exploitable reserve } \\
\left(\mathrm{m}^{3} / \text { day }\right)\end{array}$} & \multicolumn{2}{|c|}{$\begin{array}{l}\text { Secure exploitable reserve } \\
\left(\mathrm{m}^{3} / \text { day }\right)\end{array}$} \\
\hline & $\mathrm{qp}_{3}$ & $\mathrm{n}_{1}{ }^{3}$ & $\mathrm{qp}_{3}$ & $\mathrm{n}_{1}^{3}$ & $\mathrm{qp}_{3}$ & $\mathrm{n}_{1}^{3}$ \\
\hline A & $1,929.0$ & 452.7 & 433,679 & 146,056 & 35,607 & 10,059 \\
\hline B1 & 590.5 & $387 ., 8$ & 170,785 & 127,137 & 33,713 & 6,679 \\
\hline $\mathrm{B} 2$ & 162.4 & $1,115.0$ & 36,575 & 334,778 & 6,202 & 4,799 \\
\hline B3 & & 315.7 & & 93,914 & & 1,577 \\
\hline $\mathrm{C} 1$ & & 50.4 & & 702 & & 581 \\
\hline $\mathrm{C} 2$ & & & & & & \\
\hline $\mathrm{D}$ & 74.6 & 29.2 & 14,571 & 11,033 & 503 & \\
\hline $\mathrm{E}$ & & & & & 0 & \\
\hline Tổng & $2,756.5$ & $2,350.8$ & 655,611 & 713,620 & 76,025 & 23,695 \\
\hline
\end{tabular}

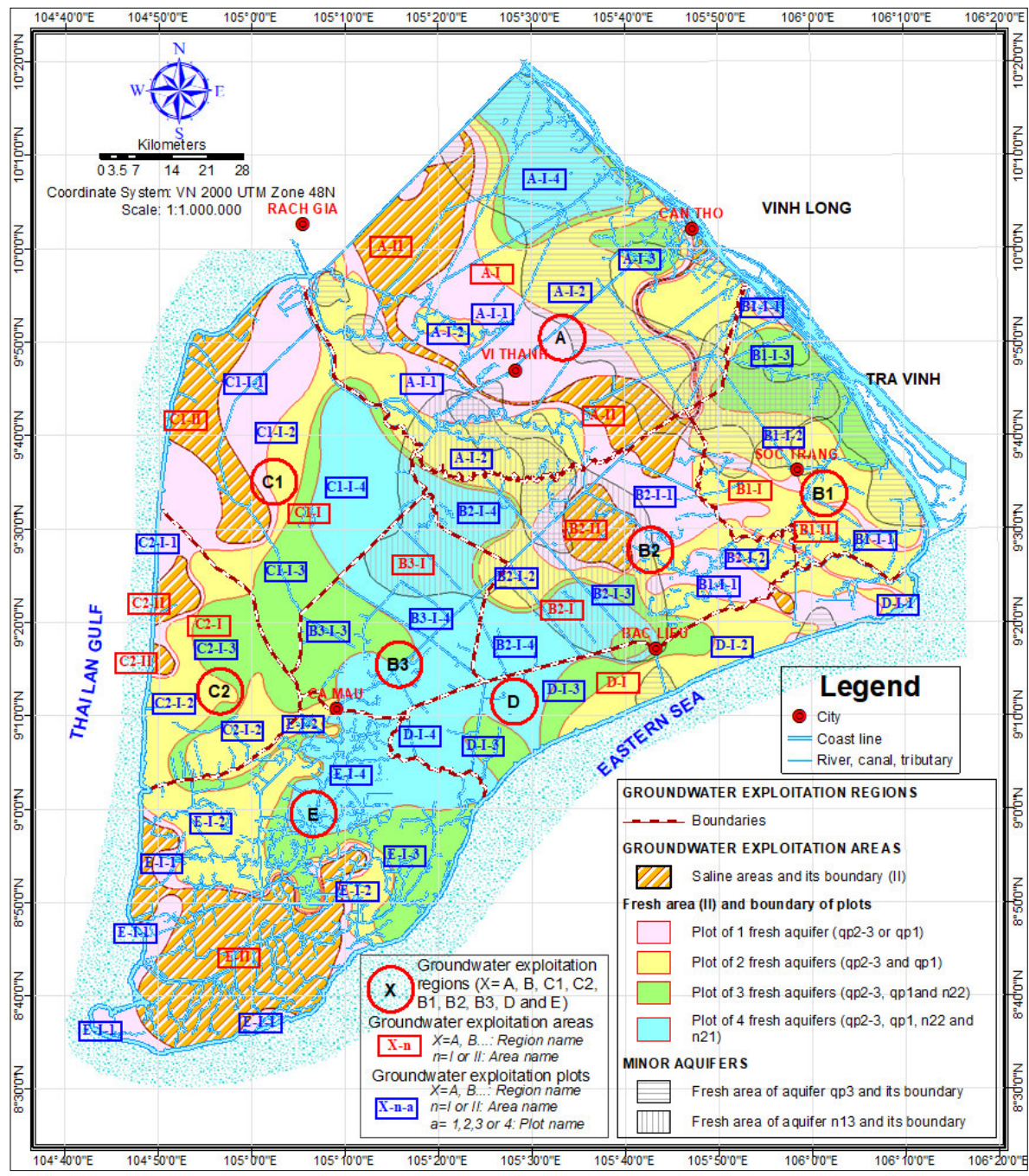

Figure 3. Map of groundwater exploitation zoning of Camau peninsula

\section{Conclusion}

Results of map of groundwater exploitation zoning on scale 1:200,000 of Camau peninsula help readers to easily know potential exploitable groundwater reserve in each ecological regions. Besides, concrete information regarding number of aquifers and secure exploitable reserve are presented in details. This is essential information for management of licensing groundwater exploitation, zoning prohibition and restriction of groundwater exploitation in accordance with Decree 167/2018/ND-CP; orientation of groundwater exploitation and use of 
groundwater sources in socio-economical development planning or allocation of water sources in water resources planning (according to Circular 42/2015/TT-BTNMT).

In groundwater exploitation zoning in this paper just considering water as fresh when having TDS $<1.0 \mathrm{~g} / 1$ ( $Q C V N 09,2015)$. Practically, in localities of scarce water sources such as coastal area in southern part of Ca Mau province and some areas in Kien Giang, Bac Lieu and Soc Trang provinces people also exploit and use groundwater having TDS $=1.0 \div 1.5 \mathrm{~g} / 1$.

\section{References}

Chan, N.,D(2010), Report on results of project Planning exploitation, use and protection of groundwater resources of Soc Trang province to 2020 (map of groundwater exploitation perspective of Soc Trang province on scale 1:50,000), Department of natural Resources and Environment of Soc Trang province;

Hien, N., T\& Quang, N.,H.(2009), Report on results of scientific-technological theme of ministerial level: Study of scientific and practical background for determining criteria for zoning groundwater exploitation, restriction and prohibition; pilot application for downstream area of Dongnai-Saigon river; Institute of Geology and Minerals; Hanoi.

Linh, T., H. (1992), Map of groundwater exploitation perspective on scale 1:50,000 of Bien Hoa-Long Thanh area (belongs to project: hydrogeological and engineering geological mapping on scale 1:50,000 of Bien HoaLong Thanh area), Department of Geology and Minerals (former).

Tuan, A., T. (1992), Map of groundwater exploitation perspective on scale 1:50,000 of Long Thanh-Vung Tau area (belongs to project: hydrogeological and engineering geological mapping on scale 1:50,000 of Long Thanh-Vung Tau area), Department of Geology and Minerals (former).

Dzung, N., H. (2004), Theme Neogene-Quaternary stratification and study of geological construction in Nambo Plain area; Ministry of Natural Resources and Environment (archived in National Center for Scientific and Technological Information, code 6949/KQ-TTKHCN), Hanoi.

Southern Institute of Water Resources Planning. (2007), Project Water Resources Planning in Camau Peninsula (archive in Ministry of Agriculture and Rural Development, Vietnam).

QCVN09(2015).National Technical Regulation on Ground Water Quality, Ministry of Natural Resources and Environment (MONRE), Vietnam. 